\title{
DESENVOLVIMENTO PÓS-EMBRIONÁRIO DE PAGURUS BREVIDACTYLUS (STIMPSON, 1858) (DECAPODA, PAGURIDAE), EM LABORATÓRIO
}

\author{
Maria Lúcia Negreiros-Fransozo ${ }^{1}$ \\ Nilton José Hebling ${ }^{2}$
}

\begin{abstract}
All the larval stages of the hermit crab Pagurus brevidactylus were studied in the laboratory, with special emphasis on external morphology and on the duration of each stage. The larvae were kept in individual containers, with water of $35 \%$ salinity and fed on nauplii of Artemia salina; room temperature was maintained at $24 \pm 1{ }^{\circ} \mathrm{C}$. The post-embryonic development includes four stages of zoea and one of megalopa. All the larval stages are drawn and described in detail.
\end{abstract}

\section{INTRODUÇÃO}

Entre os Anomura, de acordo com Hebling \& Brossi Garcia (1981), o gênero Pagurus é um dos mais conhecidos com respeito ao desenvolvimento pós-embrionário, embora as descrições dos estágios de algumas espécies sejam um tanto breves ou parciais.

Dentre as 16 espécies da família Paguridae com ocorrência no Brasil, apenas 7 pertencem ao gênero Pagurus e destas, apenas $P$. exilis e $P$. criniticornis foram estudadas quanto à metamorfose por, respectivamente, Scelzo \& Boschi (1969) e Hebling \& Brossi-Garcia (1981).

Pagurus brevidactylus (Stimpson, 1858), de acordo com McLaughlin (1975), corresponde à mesma espécie descrita por Provenzano (1959) como Pagurus miamensis, originária da Flórida, e às subespécies $P$. miamensis miamensis e $P$. miamensis uncifer, estabelecidas por Forest \& Saint Laurent (1967) e mencionadas por Coelho \& Ramos (1972) como pertencentes à fauna do Brasil. Com o reconhecimento desta sinonimia,

Trabalho realizado con auxilio do CNPq.

1. Departamento de Zoologia, Instituto Básico de Biologia Médica e Agrícola, UNESP, Campus de Botucatu, C.P. 502, CEP 18610 - Botucatu, SP.

2. Departamento de Zoologia, Instituto de Biociências, UNESP, Campus de Rio Claro, C.P. 178, CEP 13500 - Rio Claro, SP. 
a distribuição geográfica de $P$. brevidactylus, que era limitada à região do Atlântico Ocidental compreendida entre as Bermudas e nordeste da Flórida até o norte da América do Sul, ficou bastante ampliada, com vários registros de ocorrência no litoral brasileiro, até o limite meridional de $23^{\circ} 30^{\prime} \mathrm{S}$.

O objetivo principal do presente trabalho é o estudo, sob condições de laboratório, do desenvolvimento pós-embrionário de $P$. brevidactylus, com descrições morfológicas de cada um dos estágios larvais, os intervalos de tempo entre as ecdises sucessivas e um estudo comparativo com outras espécies, particularmente $P$. exilis e $P$. criniticornis.

\section{MATERIAL E MÉTODOS}

As coletas de Pagurus brevidactylus (Stimpson, 1858) foram efetuadas no litoral norte do Estado de São Paulo, nas praias dos municípios de Ubatuba ( $23^{\circ} 26^{\prime}$ 'S, $45^{\circ} 05^{\prime} \mathrm{W}$ ) e São Sebastião ( $\left.23^{\circ} 49^{\prime} \mathrm{S}, 45^{\circ} 24^{\prime} \mathrm{W}\right)$, ligeiramente ao sul da área de distribuição conhecida para esta espécie. Os exemplares foram encontrados preferencialmente em substrato rochoso revestido por algas ou colônias de Zoanthidea, em águas relativamente calmas.

No laboratório, as fêmeas ovígeras foram isoladas em aquários com aproximadamente 10 litros de água do mar, com salinidade de $35 \%$, sob aeração contínua, em uma sala climática com temperatura de $24 \pm 1^{\circ} \mathrm{C}$ e sob condições naturais de fotoperiodismo, até a eclosão das larvas.

Após a eclosão, as larvas (zoeas I) destinadas ao estudo do desenvolvimento pós-embrionário foram atraídas por um foco de luz, removidas do aquário com auxílio de um conta-gotas e transferidas isoladamente para placas de Petri de $20 \mathrm{ml}$, providas de água do mar previamente filtrada e aerada, sob as mesmas condições de temperatura e salinidade em que éclodiram.

Como alimento foram oferecidos cerca de 40 náuplios recémeclodidos de Artemia salina, para cada larva, introduzidos diariamente nas placas, após a troca de água.

As larvas de cada estágio foram fixadas e conservadas em uma mistura de álcool etílico $96 \%$ e glicerina, na proporção $1: 1$. As exúvias foram colocadas em lâminas e conservadas em glicerina pura.

As ilustrações, medidas e descrições morfológicas das zoeas e megalopas, bem como de todos os seus apêndices, foram efetuados com o auxílio de um microscópio óptico comum, provido de câmara clara, além de um estereomicroscópio, provido de ocular micrométrica, utilizandose animais conservados e exúvias, em número de 10 indivíduos para cada estágio. O comprimento total das larvas foi obtido entre o ápice do rosto 
e a margem posterior mediana do telso, excluindo os processos terminais. A criação das larvas, no laboratório, foi realizada, em linhas gerais, segundo as metodologias descritas por Hebling \& Fransozo (1982) e Negreiros-Fransozo \& Hebling (1983).

\section{RESULTADOS}

O desenvolvimento pós-embrionário de $P$. brevidactylus é constituído por uma fase de zoea, composta por 4 estágios e uma fase de mégalopa com apenas 1 estágio. Após a megalopa inicia-se o desenvolvimento juvenil. Por ocasião da eclosão das larvas não foi verificada a presença do estágio de pré-zoea.

Os resultados referentes à duração e à sobrevivência dos estágios larvais são demonstrados na Tabela I.

\section{Zoea I}

(Fig. 1-I a 6-I)

Comprimento total: $1,1 \mathrm{~mm}$.

A carapaça (Fig. 1-I) apresenta a margem posterior côncava e as margens laterais ligeiramente convexas, conferindo-lhes uma forma geral sub-retangular, com 1 par de espinhos póstero-laterais. $\mathrm{O}$ rostro não alcança as extremidades distais das cerdas antenais. Os olhos são sésseis. O 2 . $, 33^{\circ}, 4^{\circ}$ e $5^{\circ}$. somitos abdominais apresentam o bordo posterior serrilhado e com um par de espinhos póstero-laterais. O $6^{\circ}$. somito é fundido ao telso. Ește (Fig. 2-I) apresenta o bordo distal convexo, com um entalhe mediano que o divide em 2 partes simétricas, providas, cada uma, de 7 processos terminais que lhe conferem a fórmula $7+7$. O $1^{\circ}$. processo é um pequeno espinho póstero-lateral, o $2^{\circ}$. é 1 pequena cerda simples e os demais são longas cerdas plumosas.

Antênula (Fig. 3 A-I) - Unirreme e não segmentada. Em sua porção distal inserem-se 2 estetos e 2 cerdas plumosas e na extremidade subdistal, 1 longa cerda plumosa.

Antena (Fig. 3 B-I) - Com exopodito bem desenvolvido, provido de 8(9) cerdas plumosas e 1 cerda simples. Em sua margem distal externa apresenta 1 espinho bem desenvolvido. Endopodito menor que o exopodito, com 2 cerdas plumosas distais. Protopodito com 1 pequeno espinho plumoso, na região mediana distal.

Mandíbula (Fig. 4 A-I) - Constituída por várias cristas com projeções dentiformes, de ápices córneos, tanto no processo incisivo como no molar. Não há palpo mandibular.

Maxílula (Fig. 4 B-I) - Endopodito trisegmentado, provido de 1 cerda plumosa no $1^{\circ}$ segmento, 1 no $2^{\circ}$ e 2 no $3^{\circ}$. Endito basal com 2 
processos espinulados e endito coxal com 5 espinhos plumosos e 1 liso.

Maxila (Fig. 5 A-I) - Exopodito com 5 cerdas plumosas. Endopodito com 3 cerdas plumosas terminais e 2 subterminais. Endito basal com 4 cerdas plumosas no lobo distal e 3 no proximal. Endito coxal com 3 cerdas plumosas no lobo distal e 6 no proximal.

Primeiro maxilipede (Fig. 5 B-I) - Basipodito com 8 cerdas plumosas. Endopodito pentasegmentado com, respectivamente, 2, 2, 1, 2 e 4(5) cerdas plumosas na face interna, do segmento proximal para o distal, além de finas cerdas simples na margem externa de todos os segmentos. Exopodito com 4 cerdas plumosas.

Segundo Maxilipede (Fig. 6 A-I) - Basipodito com 3 cerdas plumosas. Endopodito tetrasegmentado com, respectivamente, 2, 2, 2 e 5 cerdas plumosas na face interna, do segmento proximal para o distal, além de finas cerdas simples na margem externa do $2^{\circ}$ e $3{ }^{\circ}$ segmentos. Exopodito com 4 cerdas plumosas.

Terceiro maxilípede (Fig. 6 B-I) - Apêndice pouco desenvolvido, limitado a um exopodito rudimentar, liso, bisegmentado.

\section{Zoea II}

(Figuras 1-II a 6-II)

Comprimento total: $1,3 \mathrm{~mm}$.

A carapaça (Fig. 1-II) apresenta as margens laterais convexas e a margem posterior côncava, com um par de espinhos póstero-laterais. A extremidade do rostro ultrapassa os apêndices antenais e antenulares. Os olhos são sésseis. Os somitos abdominais apresentam o bordo posterior serrilhado e 1 par de pequenos espinhos póstero-laterais. O $6^{\circ}$ somito permanece fundido ao telso. O telso (Fig. 2-II) apresenta a morfologia geral semelhante à da zoea $\mathrm{I}$, mas a sua fórmula é $8+8$, pela adição de 1 par de processos na região mediana.

Antênula (Fig. 3 A-II) - Unirreme e não segmentada. Em sua extremidade distal inserem-se 2 estetos e 2 cerdas plumosas e, subdistalmente, 1 longa cerda plumosa.

Antena (Fig. 3 B-II) - Bastante semelhante à da zoea I mas o exopodito perde a cerda simples e apresenta sempre 9 cerdas plumosas.

Mandíbula (Fig. 4 A-II) - Apresenta-se variável de um indivíduo para outro, com relação ao nível de inserção e número das cristas e dentes. Não há palpo mandibular.

Maxílula (Fig. 4 B-II) - Endopodito trisegmentado, provido de 1 cerda plumosa no $1^{\circ}$ segmento, 1 no $2^{\circ}$ e e 2 no $33^{\circ}$. O endito basal apresenta 4 processos espinulados e o endito coxal 5 espinhos plumosos e 2 lisos.

Maxila (Fig. 5 A-II) - Exopodito com 6 cerdas plumosas. Endopodito com 2 cerdas plumosas terminais e 2 subterminais. Endito basal com 

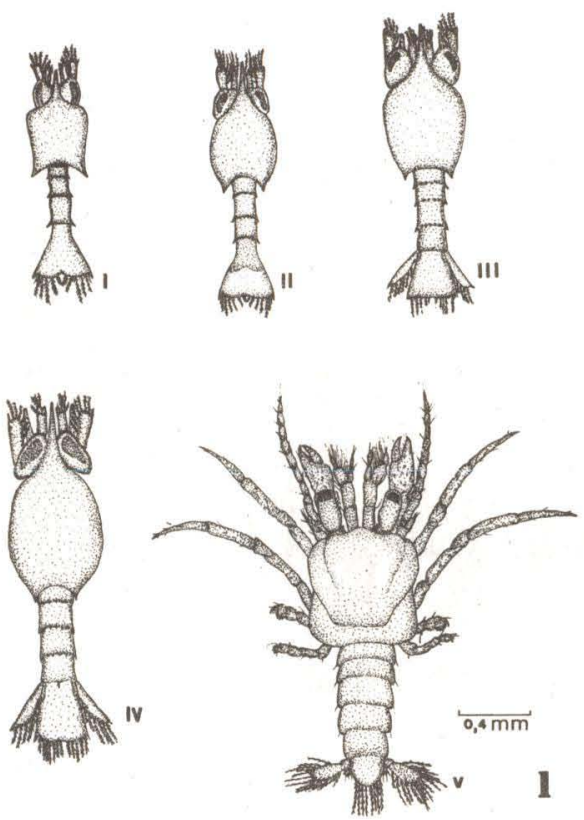

Fig. 1: Pagurus brevidactylus (Stimpson, 1858). Vista dorsal; I, II, III e IV, estágios de zoea; V, megalopa.
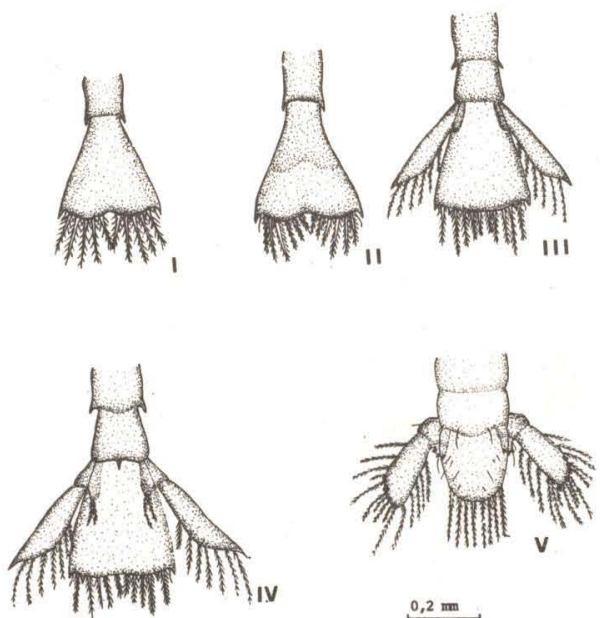

$0,2 \mathrm{~mm}$

Fig. 2: Pagurus brevidactylus (Stimpson, 1858). Vista dorsal do telso; I, II, III e IV, estágios de zoea; V, megalopa. 

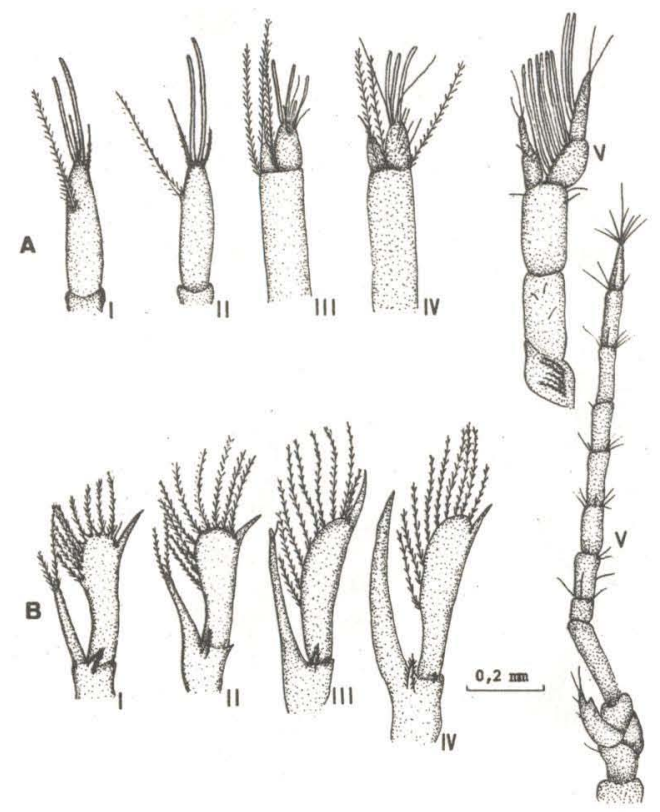

Fig. 3: Pagurus brevidactylus (Stimpson, 1858). A, antênula. B, antena. I a IV, estágios de zoea. V, megalopa.

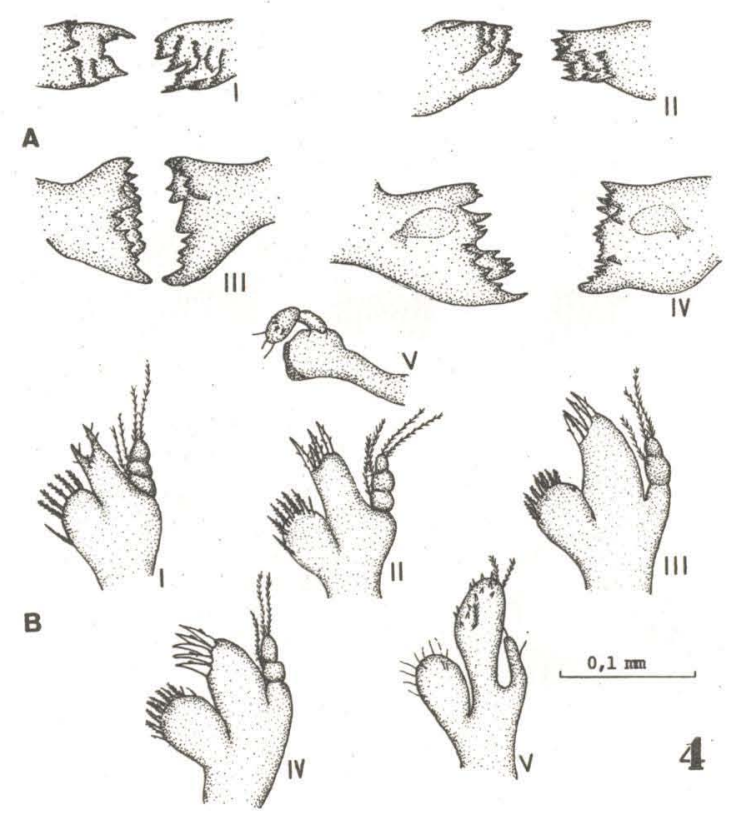

Fig. 4: Pagurus brevidactylus (Stimpson, 1858). A, mandibula. B, maxílula. I a IV, estágios de zoea e V, megalopa. 


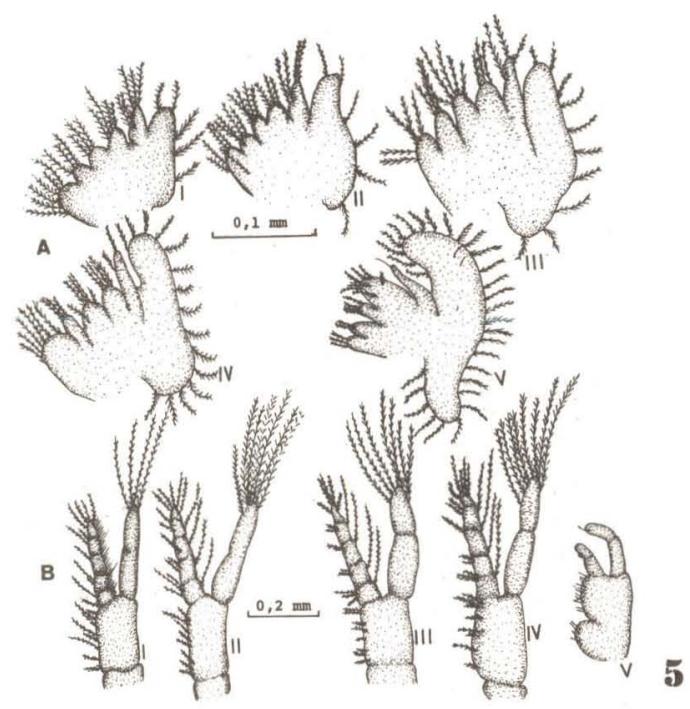

Fig. 5: Pagurus brevidactylus (Stimpson, 1858). A, maxila. B, primeiro maxilípede. I a IV, estágios de zoea. V, megalopa.
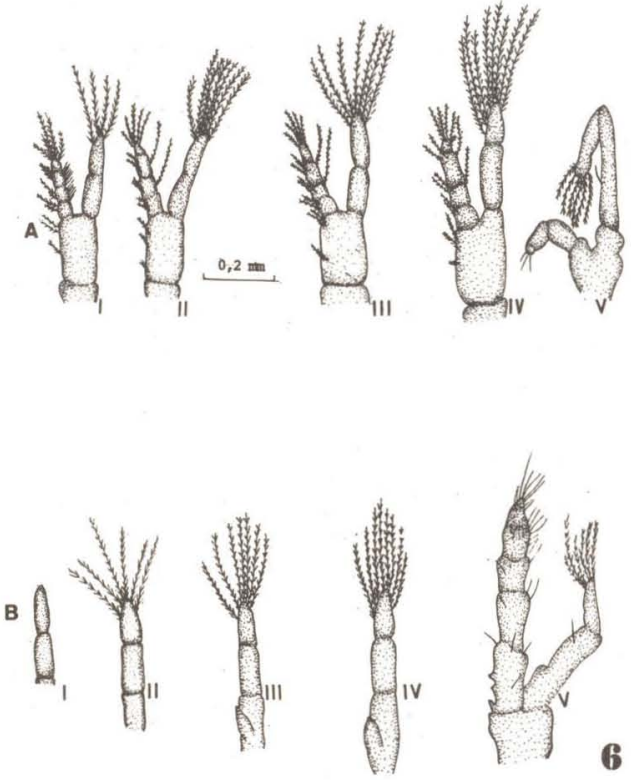

Fig. 6: Pagurus brevidactylus (Stimpson, 1858). A, segundo maxilípede. B, terceiro maxilipede. I a IV, estágios de zoea. V, megalopa. 


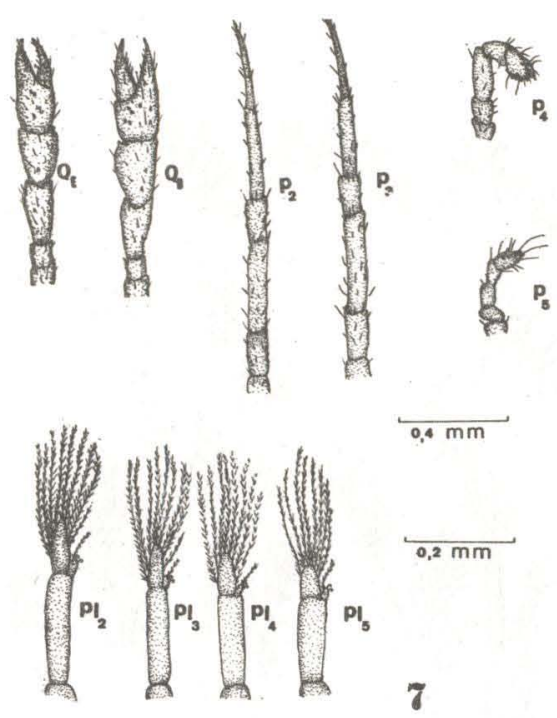

Fig. 7: Pagurus brevidactylus (Stimpson, 1858). Estágio de megalopa. QE e QD, quelípodos esquerdo e direito; $\mathrm{P}_{2}, \mathrm{P}_{3}, \mathrm{P}_{4}$ e $\mathrm{P}_{5}$, pereiópodos; $\mathrm{Pl}_{2}, \mathrm{Pl}_{3}, \mathrm{Pl}_{4}$ e $\mathrm{Pl}_{5}$, pleópodos.

3 cerdas plumosas no lobo distal e 4 no proxinial. Endito coxal com lobo distal provido de 4 cerdas plumosas e proximal de 5 .

Primeiro maxilipede (Fig. 5 B-II) - Basipodito com 8 cerdas plumosas. Endopodito com, respectivamente, 3, 2, 1, 2 e 5 cerdas plumosas na face interna, do segmento proximal para o distal, além de 1 longa cerda plumosa na margem externa do $1^{\circ}$ ao $4^{\circ}$. segmentos. Exopodito com 7 cerdas plumosas.

Segundo maxilipede (Fig. 6 A-II) - Basipodito com 3 cerdas plumosas. Endopodito com, respectivamente, 2, 2, 2 e 5 cerdas plumosas na face interna, do segmento proximal para o distal, além de 1 cerda plumosa na face externa do $2^{\circ}$ e e $3^{\circ}$ segmentos. Exopodito com 7 cerdas plumosas.

Terceiro maxilipede (Fig. 6 B-II) - Limitado a um exopodito bisegmentado, com 6 cerdas plumosas no segmento distal.

\section{Zoea III}

(Fig. 1-III a 6-III)

Comprimento total: $1,45 \mathrm{~mm}$.

A carapaça (Fig. 1-III) é semelhante à da zoea II, com o rostro ligeiramente maior. Os olhos são sésseis. Os somitos abdominais apresentam o bordo posterior serrilhado, com 4(5) pequenas saliências e 1 par de espinhos póstero-laterais. $\mathrm{O}^{\circ}{ }^{\circ}$ somito individualiza-se. $\mathrm{O}$ telso (Fig. 2-III) 
permanece com a fórmula $8+8$ mas o seu 4 . processo terminal funde-se à sua margem distal, como o 1 . . Neste estágio surge o urópodo, não segmentado, com 6 cerdas plumosas marginais e 1 pequeno espinho distal.

Antênula (Fig. 3 A-III) - Birreme e segmentada. Exopodito com 3(4) estetos e 3 cerdas simples e endopodito com 1 cerda plumosa. Pedúnculo com 2 cerdas plumosas, em sua extremidade distal.

Antena (Fig. 3 B-III) - Exopodito com 9 cerdas plumosas e 1 espinho. Endopodito com 1 cerda simples terminal. Protopodito com 1 pequeno espinho simples lateral e 1 espinho plumoso mediano.

Mandíbula (Fig. 4 A-III) - Sem palpo. Apresenta-se com numerosos dentes e bem mais desenvolvida, quando comparada ao estágio anterior.

Maxílula (Fig. 4 B-III) - Endopodito bisegmentado, provido de uma cerda plumosa no 1 . segmento e 2 no $2{ }^{\circ}$. Endito basal com 4 processos espinulados e endito coxal com 7 espinhos plumosos.

Maxila (Fig. 5 A-III) - Exopodito com 10 cerdas plumosas. Endopodito com 3 cerdas plumosas terminais. Enditos basal e coxal com 3 cerdas plumosas no lobo distal e 5 no proximal.

Primeiro maxilipede (Fig. 5 B-III) - Basipodito com 8 cerdas plumosas. Endopodito com, respectivamente, 3, 2, 1, 2 e 5 cerdas plumosas na face interna, do segmento proximal para o distal, além de 1 cerda plumosa na face externa do $1^{\circ}$ ao $4^{\circ}$. segmentos. Exopodito com 7 cerdas plumosas.

Segundo maxilípede (Fig. 6 A-III) - Basipodito com 3 cerdas plumosas. Endopodito com, respectivamente, 2, 2, 2 e 5 cerdas plumosas na face interna, do segmento proximal para o distal, além de 1 cerda plumosa na face externa do $2^{\circ}$ e $3^{\circ}$. segmentos. Exopodito com 7 cerdas plumosas.

Terceiro maxilípede (Fig. 6 B-III) - Exopodito bisegmentado, com 7 cerdas plumosas. Endopodito rudimentar.

\section{Zoea IV}

(Fig. 1-IV a 6-IV)

Comprimento total: $1,8 \mathrm{~mm}$.

A carapaça (Fig. 1-IV) é alongada, com região posterior côncava. Os olhos são ligeiramente pedunculados. Os somitos abdominais apresentam o bordo posterior serrilhado e 1 par de pequenos espinhos póstero-laterais. O 6. somito abdominal possui 1 espinho mediano, póstero-dorsal. O telso (Fig. 2-IV) é muito semelhante ao da zoea III. O urópodo apresenta o protopodito individualizado, com uma projeção interna provida de 2 cerdas plumosas. Seu exopodito apresenta 1 espinho terminal e 7 cerdas plumosas marginais. Diferenciam-se, neste estágio, os rudimentos dos pereiópodos e pleópodos. 
Antênula (Fig. 3 A-IV) - Pedúnculo com 3 cerdas plumosas na extremidade distal. Exopodito com 3(4) estetos e 6 cerdas simples. Endopodito com 1 cerda simples.

Antena (Fig. 3 B-IV) - Exopodito com 9 cerdas plumosas. Endopodito liso. Protopodito com 1 espinho simples lateral e 1 espinho plumoso mediano.

Mandíbula (Fig. 4 A-IV) - Processos incisivo e molar providos de um grande número de dentes, mais desenvolvidos que na zoea III. Geralmente desprovida de palpo, embora algumas larvas possam apresentá-lo na forma de um pequeno nódulo rudimentar.

Maxílula (Fig. 4 B-IV) - Endopodito bisegmentado, semelhante ao da zoea III. Endito basal com 5 processos espinulados e endito coxal com $7(8)$ espinhos plumosos e 3 cerdas simples.

Maxila (Fig. 5 A-IV) - Exopodito com 15 cerdas plumosas. Endopodito com 2 cerdas plumosas. Endito basal com 4 cerdas plumosas no lobo distal e 5 no proximal. Endito coxal com 3 cerdas plumosas no lobo distal e 6 no proximal.

Primeiro maxilípede (Fig. 5 B-IV) - Basipodito com 8 cerdas plumosas. Endopodito com, respectivamente, 3, 2, 1, 2 e 5 cerdas plumosas na face interna, do segmento proximal para o distal, além de uma cerda plumosa na face externa do $1^{\circ}$ ao $4^{\circ}$. segmentos. Exopodito com 8 cerdas plumosas.

Segundo maxilípede (Fig. 6 A-IV) - Basipodito com 3 cerdas plumosas. Endopodito com, respectivamente, 2, 2, 2 e 5 cerdas plumosas na face interna, do segmento proximal para o distal, além de uma cerda plumosa na face externa do $2^{\circ}$ e e $3^{\circ}$ segmentos. Exopodito com 8 cerdas plumosas.

Terceiro maxilípede (Fig. 6 B-IV) - Semelhante ao da zoea III mas com 8 cerdas piumosas no exopodito.

\section{Megalopa}

(Fig. 1-V a 6-V e 7)

Comprimento total: $1,4 \mathrm{~mm}$.

O cefalotórax (Fig. 1-V) é quadrangular, com o rostrum bastante reduzido e arredondado no ápice. Os olhos são pedunculados. Na base do pedúnculo ocular aparece a escama ocular, provida de apenas 1 espinho. É neste estágio que se diferenciam completamente os pereiópodos e pleópodos. Os somitos abdominais são em número de seis, mais largos que longos. Os pleópodos são em número de 4 pares, dispostos ventralmente, do $2^{\circ}$ ao $5^{\circ}$ somitos abdominais. O leque caudal torna-se completo. $\mathrm{O}$ telso (Fig. 2-V) apresenta-se bastante modificado em relação aos dos estágios de zoea. Sua forma é sub-retangular, com 8 cerdas plumosas terminais e algumas cerdas simples distribuídas por toda a superfície. $\mathrm{O}$ 
protopodito de cada urópodo possui 2 ou 3 cerdas simples. $\mathrm{O}$ exopodito apresenta 15 cerdas plumosas e 5 nódulos córneos enquanto o endopodito possui 2(3) cerdas simples e 3 nódulos córneos.

Antênula (Fig. $3 \mathrm{~A}-\mathrm{V}$ ) - Pedúnculo antenular trisegmentado. O segmento proximal sustenta 5 pequenas cerdas plumosas; o segmento mediano e o distal apresentam 3 cerdas simples cada um. Endopodito bisegmentado, com 3 cerdas simples em cada segmento. Exopodito bisegmentado com 6 estetos no segmento proximal e 2 estetos e 2 cerdas simples no segmento distal.

Antena (Fig. 3 B-V) - Pedúnculo composto por 5 segmentos mais a escama. No $2^{\circ}$ segmento ocorre uma cerda simples. $\mathrm{O}$ exopodito sofreu, em relação aos estágios de zoea, uma enorme redução em tamanho e número de cerdas, possuindo apenas 4 ou 5 cerdas simples. Flagelo antenal ou endopodito com 8 segmentos providos de, respectivamente, 3, 3, 6, 5, 1, 6, 4 e 8 cerdas simples, do segmento proximal para o distal.

Mandíbula (Fig. $4 \mathrm{~A}-\mathrm{V}$ ) - Semelhante à do adulto. Aparece o palpo, bisegmentando, com 3 cerdas simples e 4 minúsculos espinhos no segmento distal. A porção correspondente aos processos incisivo e molar modifica-se em uma lâmina cortante.

Maxilula (Fig. 4 B-V) - O endopodito diminui em tamanho, perde a segmentação que ocorria nas zoeas e é provido de apenas 2 cerdas simples. Endito coxal com 5 a 11 cerdas simples e basal com 13 pequenos espinhos e 3 cerdas plumosas.

Maxila (Fig. 5 A-V) - Exopodito com 24 a 30 cerdas plumosas marginais e 2(3) cerdas simples, medianas. Endopodito com apenas 1 cerda simples. Enditos basal e coxal com várias cerdas plumosas, que variam em número e tamanho de um indivíduo para outro.

Primeiro maxilípede (Fig. 5 B-V) - Completamente modificado em relação aos estágios de zoea. Seu basipodito torna-se bilobado, com o lobo proximal provido de 4 cerdas simples e o distal de 12 a 14 . O endopodito é liso e bisegmentado. $\mathrm{O}$ exopodito, também bisegmentando, possui apenas 1 cerda simples terminal.

Segundo maxilípede (Fig. $6 \mathrm{~A}-\mathrm{V}$ ) - Protopodito liso. Exopodito alongado, bisegmentado, com 1 cerda simples no segmento proximal e 6 cerdas plumosas no distal. Endopodito trisegmentando, com 3 cerdas simples no segmento distal.

Terceiro maxilipede (Fig. 6 B-V) - Protopodito liso. Exopodito bisegmentado, com 1 cerda simples no segmento proximal e 6 cerdas plumosas no distal. Endopodito pentasegmentado com, respectivamente, 4, $3,4,10$ e 9 cerdas simples, do segmento proximal para o distal. No 1 ? segmento do endopodito, que corresponde ao isquiopodito, evidencia-se uma pequena "crista dentata".

Quelipodos (Fig. 7 QE e QD) - Subiguais, com o direito ligeiramente maior que o esquerdo. Ambos são revestidos de pequenas cerdas 
simples, com os carpos providos de 1 pequeno espinho, na margem distal interna. O comprimento do dáctilo (dedo móvel) corresponde, aproximadamente, à metade do comprimento da mão.

Segundo e terceiro pereiópodos (Fig. $7 \mathrm{P}_{2}$ e $\mathrm{P}_{3}$ ) - Muito semelhantes na estrutura geral. Apresentam o dáctilo agudo, ligeiramente maior ou igual ao própodo. Ambos os apêndices são recobertos por diminutas cerdas simples, esparsas.

Quarto pereiópodo (Fig. $7 \mathrm{P}_{4}$ ) - Subquelado, bem menor que o $2^{\circ}$. e 3 . pereiópodos. O própodo apresenta várias cerdas simples e 5(6) grânulos córneos. O mero é o maior segmento deste apêndice.

Quinto pereiópodo (Fig. $7 \mathrm{P}_{5}$ ) - Pouco menor que o 4. pereiópodo. $\mathrm{O}$ própodo é provido de 3 grânulos córneos, além de cerdas simples. $\mathrm{O}$ dáctilo possui várias cerdas simples e 2 grânulos córneos.

Pleópodos (Fig. $7 \mathrm{Pl}_{2}$ a $\mathrm{Pl}_{5}$ ) - Os 4 pares de pleópodos apresentam a mesma configuração geral, com 9 cerdas plumosas no exopodito dos 2 primeiros pares $\left(\mathrm{Pl}_{2}\right.$ e $\left.\mathrm{Pl}_{3}\right)$ e 8 no 3. e 4..$\left(\mathrm{Pl}_{4}\right.$ e $\left.\mathrm{Pl}_{5}\right)$, além de 1 cerda plumosa e 2 pequenas cerdas unciformes no endopodito. Do 1 ? para o 4 . par, os pleópodos diminuem ligeiramente no comprimento.

\section{DISCUSSÃO}

Entre as espécies da família Paguridae com desenvolvimento pósembrionário conhecido, o número de estágios de zoea é sempre 4 , fato confirmado com os estudos de $P$. brevidactylus.

A duração média do desenvolvimento pós-embrionário de $P$. brevidactylus é muito diferente de $P$. exilis, estudados, respectivamente, por Hebling \& Brossi-Garcia (1981) e Scelzo \& Boschi (1969), embora esta variável esteja diretamente correlacionada com a temperatura em que foram processadas as criações. Um exemplo marcante desta variação foi demonstrado por Dawirs (1979), para P. bernhardus, cujos períodos de desenvolvimento foram de 33, 49 e 107 dias quando mantidos em temperaturas de, respectivamente, 18,12 e $6^{\circ} \mathrm{C}$.

Com relação à morfologia geral das fases larvais de outras espécies do gênero Pagurus com ocorrência no Brasil, Hebling \& Brossi-Garcia (1981) apresentaram uma série de caracteres que permitem as identificações específicas das zoeas e megalopas de $P$. criniticornis e $P$. exilis. Considerando-se tais caracteres e os apresentados por $P$. brevidactylus constatou-se que, independentemente do estágio considerado, as zoeas destas 3 espécies podem ser identificadas pela simples presença e disposição dos espinhos nos segmentos abdominais e pelo número de cerdas que ocorrem no basipodito do primeiro maxilipede. Assim, as zoeas de $P$. criniticornis não apresentam espinhos nos segmentos abdominais ou, quando muito, minúsculas projeçðes póstero-laterais; as zoeas de $P$. brevidactylus apresentam os 4 primeiros segmentos serrilhados na região 
póstero-dorsal e com 1 par de pequenos espinhos póstero-laterais; as zoeas de $P$. exilis apresentam, além de um par de pequenos espinhos póstero-laterais nos 4 primeiros segmentos, um par adicional, muito desenvolvido, no quinto segmento abdominal. Com relação ao número de cerdas presentes no basipodito do primeiro maxilípede, constatou-se que em $P$. criniticornis ocorrem 4 a 6, em $P$. brevidactylus 8 e em $P$. exilis 10 .

$\mathrm{Na}$ fase de megalopa as distinções específicas podem ser obtidas pelos seguintes caracteres: flagelo antenal com 5 ou 6 artículos em $P$. criniticornis, 8 em $P$. brevidactylus e cerca de 14 em $P$. exilis; escafognatito da maxila com 20 cerdas plumosas em $P$. criniticornis, 24 a $30 \mathrm{em} P$. brevidactylus e cerca de 35 em $P$. exilis.

Acrescente-se ainda que, em termos práticos, o tamanho de um determinado estágio do desenvolvimento pode se caracterizar como uma variável muito importante nas identificaçð̃es específicas de $P$. criniticornis, $P$. brevidactylus e $P$. exilis, cujos valores são apresentados na Tabela II.

\section{Tabela I}

P. brevidactylis: Duração e sobrevivência dos estágios larvais, a partir do nascimento. $\overline{\mathrm{X}}$, duração média acumulada (em dias); D e D', duração mínima e máxima; $n$, número de indivíduos vivos, $\dagger$, número de indivíduos mortos;

$\mathrm{S}$, porcentagem de sobrevivência.

\begin{tabular}{lrrrrrl}
\hline Estágios & $\overline{\mathrm{X}}$ & $\mathrm{D}$ & $\mathrm{D} \mathrm{D}^{\prime}$ & $\mathrm{n}$ & $\dagger$ & $\mathrm{S}$ \\
\hline Zoea I & 2,9 & 2 & 6 & 40 & 10 & 80 \\
Zoea II & 6,5 & 6 & 8 & 30 & 10 & 60 \\
Zoea III & 12,3 & 11 & 14 & 24 & 6 & 48 \\
Zoea IV & 17,6 & 16 & 19 & 20 & \multicolumn{1}{c}{4} & 40 \\
Megalopa & 28,2 & 26 & 30 & 8 & 12 & \multicolumn{1}{c}{16} \\
\hline
\end{tabular}

Tabela II

Comprimento total, em milímetros, dos estágios de zoea e megalopa de Pagurus brevidactylus, Pagurus criniticornis e Pagurus exilis.

\begin{tabular}{lccc}
\hline Estágios & P. brevidactylus & P. criniticornis & P. exilis \\
\hline Zoea I & 1,1 & 1,6 & 2,5 \\
Zoea II & 1,3 & 2,0 & 2,8 \\
Zoea III & 1,45 & 2,3 & 3,2 \\
Zoea IV & 1,8 & 2,5 & 4,0 \\
Megalopa & 1,4 & 1,6 & 2,9 \\
\hline
\end{tabular}




\section{REFERENCIAS}

Coelho, P. A. \& Ramos, M. A., 1972. A constituição e a distribuição da fauna de decápodos no litoral leste da América do Sul, entre as latitudes de $5^{\circ} \mathrm{N}$ e $39^{\circ} \mathrm{S}$. Trab. Oceanogr. Univ. Fed. Pe, Recife, 13:133-236.

Dawirs, R. R., 1979. Effects of temperature and salinity on larval development of Pagurus bernhardus (Decapoda, Paguridae). Mar. Ecol. Prog. Ser. 1:323-329.

Forest, K. \& Saint Laurent, M. de 1967. Campagne de la "Calypso" au large des côtes de l'Amérique du Sud (1961 - 1962). 6. Crustacés Décapodes: Pagurides. Ann. Inst. océanogr., Monaco 45(2):47-169.

Hebling, N. J. \& Brossi-Garcia, A. L. 1981. Desenvolvimento pós-embrionário de Pagurus criniticornis (Dana, 1852) (Crustacea, Paguridae), em laboratório. Rev. Brasil. Biol. 41 (4):765-779.

Hebling, N. J. \& Fransozo, A. 1982. Desenvolvimento pós-embrionário de Paguristes erythrops Holthuis, 1959 (Decapoda, Diogenidae), em laboratório. Rev. Brasil. Biol. 42(1):117-128.

McLaughlin, P.A., 1975. On the identify of Pagurus brevidactylus (Stimpson) (Decapoda:Paguridae), with the description of a new species of Pagurus from the Western Atlantic. Bull. Mar. Sci. 25(3):359-376.

Negreiros-Fransozo, M.L. \& Hebling, N.J. 1983. Desenvolvimento pós-embrionário de Isocheles sawayai Forest \& Saint Laurent, 1967 (Decapoda, Diogenidae), em laboratório. Papéis Avulsos Zool. 35(4):41-53.

Provenzano Jr., A.J. 1959. The shallow-water hermit crabs of Florida. Bull. Mar. Sci. Gulf. Caribb. 9(4):349-420.

Scelzo, M.A. \& Boschi, E.E. 1969. Desarrollo larval del cangrejo hermitano Pagurus exilis (Benedict) en laboratorio (Crustacea, Anomura, Paguridae). Physis 29(78):165-184. 